\title{
MTA as Apical Filling Material In Internal Resorption
}

\author{
Dr Bonny Paul ${ }^{1}$,Dr Kavita Dube ${ }^{2}$,Dr Arti Rai ${ }^{3}$,Dr Swarnima Randhelia ${ }^{3}$ \\ 1(Professor,Department of Endodontics Hitkarini Dental College \& hospital, Jabalpur.India) \\ 2(Reader,Department of Endodontics. Hitkarini Dental College \& hospital,Jabalpur.India) \\ 3.(Post graduate, Department of Endodontics Hitkarini Dental College \& hospital, Jabalpur.India)
}

\begin{abstract}
Root resorption is a dental complication caused by dental trauma, surgical procedures, excessive pressure or irritation from bleaching agents that can lead to loss of tooth. This paper presents a case of internal resorption in maxillary central incisor and demonstrates the use of MTA as filling material
\end{abstract}

\section{Introduction:}

Internal root resorption is a resorptive defect of the internal aspect of the root following necrosis of odontoblasts as a result if inflammation. It is caused by transformation of normal pulp tissue into granulomatous tissue with giant cells, which resorb dentin. This transformation is thought to stem from chronic inflammation of the coronal pulp [1] caused by continuing bacterial stimulation [2]. Trauma, caries, and restorative procedures have been suggested to be contributory factors, but it also occurs as an idiopathic dystrophic change [3].

Internal root resorption is usually asymptomatic and is detected through routine radiographs or by clinical signs of pink spot on the crown. Radiographic examination usually reveals a fairly uniform radiolucent area with disrupted outline of the root canal [4]. Tissue loss can be extensive and often unrestorable.

The progress of internal resorption depends on vital tissues [5]. After considering the differential diagnosis, including external root resorption, treatment must aim at complete removal of the resorptive tissue from the root canal system, in an attempt to prevent further loss of hard tissue. However, selecting a suitable restorative material for these cases remain a challenge, especially if tooth loss is extensive, extraction is the only realistic option in some cases.

MTA was proposed by Torabinejad et al [6] and has been indicated in the literature for the treatment of resorption, specially when there is a communication with the periodontium; these are the communicating or perforating resorption. This is due to the fact that MTA has properties such a good capacity of sealing [7], biocompatibility[8], radioopacity and ability to set in presence of blood[9].

The purpose of this paper is to present an internal resorption case report using MTA as apical root filling material.

\section{Case Report}

A thirty year old female with a non contributory medical history was referred to the department of Conservative dentistry and Endodontics, Hitkarini dental college and hospital, Jabalpur, with pain in her maxillary right central incisor. Clinical examination revealed a composite restoration in the same tooth with marginal leakage. The tooth was tender to percussion with absence of sinus tract. Radiographic examination revealed an oval radiolucent area within the canal in the apical third suggestive of internal resorption along with periapical radiolucency (Fig 1). Vitality testing with a pulp tester showed a delayed response suggestive of degenerating pulp. The case was diagnosed as chronic irreversible pulpitis with internal resorption. Hence it was decided to carry out endodontic treatment using MTA as the apical filling material. An informed oral and written consent was obtained from the patient.

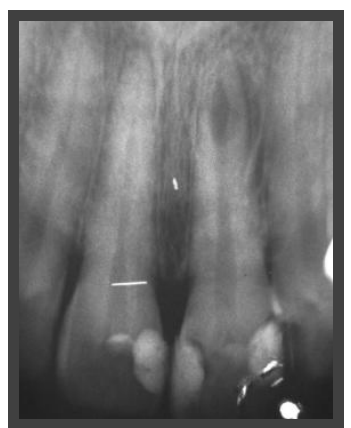

FIG 1- PREOPERATIVE RADIOGRAPH 
After anaesthesia with $2 \%$ lidocaine, a rubber dam was placed. A conventional access cavity was prepared and the root canal length was measured using an apex locater (Root ZX; Morita) and confirmed on a radiograph (Fig 2). Biomechanical preparation was performed by crown down technique using gates glidden drills (Mani) in the cervical third. The middle and apical third was instrumented using flexofiles( Dentsply Maillefer) . Irrigation was carried out using normal saline and $2 \%$ Chlorhexidine solution. An intracanal dressing of calcium hydroxide ( Vitapex) was placed and the canal orifice was sealed with a temporary dressing ( Cavit).

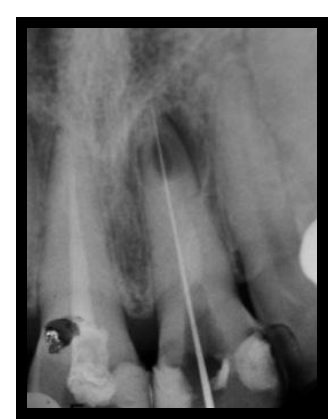

FIG 2- Working length radiograph

After two weeks the dressing was removed and and it was decided to fill the apical third of the canal with MTA ( Proroot MTA). MTA was mixed according to manufacturer's instructions and carried to apical third using MTA carrier (Fig 3). The MTA was condensed using root canal pluggers taking care to seal the resorptive area. After confirming the placement of MTA using a radiograph (Fig 4) a moist cotton pellet was placed in the canal and the canal sealed with a temporary dressing (Cavit). The dressing was removed after $48 \mathrm{hrs}$ and the hardness of set MTA was checked. As the tooth was aymptomatic the remainder of the canal was filled with gutta percha using lateral condensation technique with AH Plus (Dentsply) as sealer . A temporary dressing was given and a radiograph (Fig 5) taken to evaluate the obturation. After a week the patient was recalled back and a permanent restoration was placed.

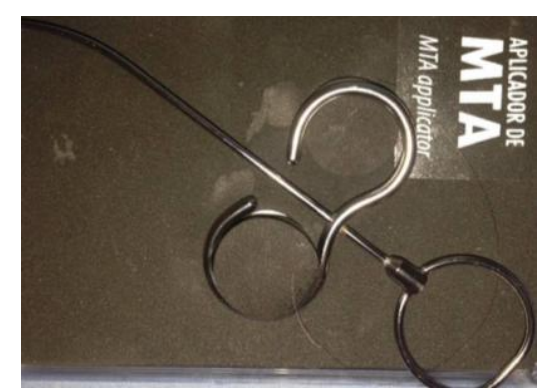

FIG 3- MTA CARRIER

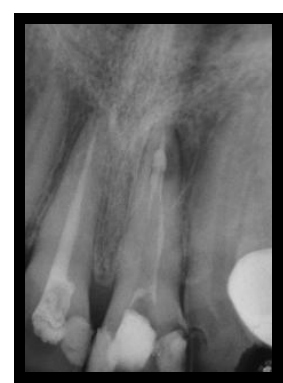

FIG 4- RADIOGRAPH AFTER MTA PLACEMENT

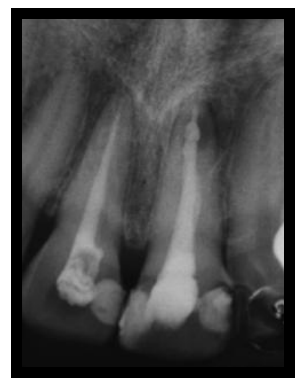




\section{FIG 5-POST OBTURATION RADIOGRAPH}

\section{Discussion}

Internal inflammatory root resorption is an insidious pathologic process, initiated within the pulp space and associated with loss of dentine. It is an oval shaped enlargement of the root canal space, usually asymptomatic and detectable by radiographs. Internal root resorption can be either transient or progressive according to a study by Wedenberg et al [1]. According to Culbreath et al [10], the treatment for internal resorption can include several mateials such as gutta percha, zinc oxide and amalgam alloy. However these materials do not provide strength to the tooth structure and may be responsible for considerable tooth discolouration. The use of a root canal dressing with a material based on calcium hydroxide between sessions was aimed at dissolving remaining pulp debris, alkalinizing the environment and controlling the periodontal bleeding [11]. Hsien et al [12] reported a a case of internal resorption with a buccal perforation in a maxillary central incisor.The apical third was obturated with gutta percha and the perforated lesion was repaired with MTA. Success was seen after one year of clinical and radiographic follow up .Sari and Sonmez [13] carried out a study on the treatment of internal resorption in deciduous molars using MTA. Their results revealed that MTA seems to be an adequate material for the treatment of internal resorptions of deciduous teeth. Meire and De Moor [14] when treating a perforating internal resorption in the maxillary second molar using MTA, observed a complete recovery of the alveolar bone and periodontal ligament. Holland et al [15] in their experiment on dog's teeth showed that when lateral perforations were sealed with MTA immediately, the results were favourable even showing healing of periodontal ligament. However not so favourable results were seen when these perforatons were sealed after 7 days. Favieri et al [16] reported that MTA is a material that induces osteogenesis, being indicated as a retrograde filling material due to its excellent marginal sealing and due to the fact that it stimulates the osteoblasts adherence.

\section{Conclusion}

It is necessary to offer our patients the best solution in complicated situation. On the basis of review of literature and clinical and radiographic outcome hereby presented, it can be said that teeth with large internal root resorption should be treated in an attempt to salvage the tooth. Because of its excellent marginal sealing and the property to stimulate osteoblastic adherence to the root surface, MTA has been considered as a good filling material to be used in communicating or perforating internal root resorption. However more clinical studies with long term follow up are required to confirm these findings.

\section{References}

[1]. Wedenberg C, Lindskog S. Experimental internal resorption in monkey teeth. Endod Dent Traumatol 1985;1:221-7.

[2]. Tronstad L. Root resorption--etiology, terminology and clinical manifestations.Endod Dent Traumatol 1988;4:241-52.

[3]. Ingle JI, Bakland LK. Endodontics. 5th ed. Hamilton: BC Decker; 2002:138 -9.

[4]. Gartner AH, Mack T, Somerlott RG, Walsh LC. Differential diagnosis of internal and external root resorption. J Endod 1976;2:329-34.

[5]. Andreasen JO. Traumatic injuries of the teeth 2nd ed. Copernhagen, Denmark: Munksgaard International Publisheers; $1981: 193$.

[6]. Torabinejad M, Hong CU\&Pitt Ford TR. Physical properties of a new root end filling material. J Endod 1995; 21: 349-53.

[7]. . Al- KahtaniA, ShostadS, SchifferleR, BhambhaniS. In- vitro evaluation of microleakage of an orthograde apical plug of mineral trioxide aggregate in permanent teeth with simulated immature apices. J Endod 2005; 31:117-9.

[8]. Mitchell PJ, PittFord TR, Torabinejad M, McDonald F.Osteoblast biocompatibility of minera ltrioxide aggregate. Biomaterials 1999; 20: 167- 73 .

[9]. TorabinejadM, HigaRK, McKendryDJ, PittFordTR. Dye leakage of four root end filling materials: effects of blood contamination. J Endod 1994; 20:159- 63.

[10]. Culbreath TE, Davis GM, West NM, Jackson A. Treating internal resorption using a syringeable composite resin. J Am Dent Assoc 2000; 131, 493-5.

[11]. Siqueira JF Jr, Lopes HP. Medicac, a o intracanal. In: Siqueira JF Jr, Lopes HP, eds. Endodontia: biologia e te' cnica, 2nd edn. Rio de Janeiro: Guanabara Koogan 2004; 581-618.

[12]. Hsien HC, Cheng YA, Lee YL, Lan WH \& Lin CP. Repair of Perforating Internal Resorption with Mineral Trioxide Aggregate: A Case Report. J Endod 2003;29(8): 538-9.

[13]. Sari S \& S“onmez D. Internal Resorption Treated with Mineral Trioxide Aggregate in a Primary Molar Tooth: 18- Month Follow-up. J Endod 2006;32(1): 69-71.

[14]. Meire M \& De Moor R. Mineral Trioxide Aggregate Repair of a Perforating Internal Resorption in a Mandibular Molar. J Endod 2008; 34(2):220-3.

[15]. Holland R, Ferreira LB, Souza V, Otoboni Filho JA, Murata SS \& Dezan Jr. E. Reaction of the lateral periodontium of dogs' teeth to contaminated and noncontaminated perforations filled with mineral trioxide aggregate. J Endod 2007; 33(10): 1192-97.

[16]. Favieri A, Campos LC, Burity VH, Santa Cec'́lia M \& Abad EC. 2008. Use of Biomaterials in Periradicular Surgery: A Case Report. J Endod. 34(4): 490-94. 